\section{RMD Open}

Rheumatic \& Musculoskeletal Diseases

To cite: Carmona L. Reducing bureaucracy in clinical trials, now is the time!. RMD Open 2022;8:e002202. doi:10.1136/ rmdopen-2022-002202

Accepted 8 February 2022

Check for updates

(C) Author(s) (or their employer(s)) 2022. Re-use permitted under CC BY-NC. No commercial re-use. See rights and permissions. Published by BMJ.

For numbered affiliations see end of article.

Correspondence to Dr Loreto Carmona; loreto.carmona@inmusc.eu

\title{
Reducing bureaucracy in clinical trials, now is the time!
}

\author{
Loreto Carmona
}

Over the last few years, clinical trials have become increasingly difficult and expensive to conduct, due in great measure to the disproportionate volume of bureaucratic demands involved. Direct consequences of the rising costs and complexity are the stagnation of clinical research in Europe, fewer academic clinical trials and limited accessibility to innovative treatments. ${ }^{1-3}$ Crucially, excessive administrative demands limit the time that clinical researchers can dedicate to their patients, with potential negative consequences for the quality of studies and patient safety.

The Biomedical Alliance in Europe (BioMed Alliance) is a non-profit organisation representing 36 European research and medical societies, including the European Alliance of Associations of Rheumatology (EULAR), with the goal of improving the health and well-being of all European citizens by promoting the interests of researchers and healthcare professionals across all medical disciplines (https://www.biomedeurope. org/). BioMed Alliance, thus, provides a platform to speak with a unified voice and interact with EU policymakers on key topics in the European healthcare field, and to ensure that the European Research Area is supported with sustainable research policies, among other aims.

Together with patient advocates, the BioMed Alliance is calling for urgent actions to diminish bureaucratic burdens and move towards more patient-centred, risk-based, pragmatic, efficient and cheaper trials. In particular, solutions are needed for the following issues:

\section{INAPPROPRIATE AND COUNTERPRODUCTIVE SAFETY REPORTING}

Conservative definitions of Suspected Unexpected Serious Adverse Reactions (SUARs) and disproportionate reporting requirements-in particular, by contract research organisations (CROs) - have led to an overwhelming volume of safety reports, which prevents clinical researchers from identifying the truly important safety signals amid an unmanageable number of trivial queries and unfiltered notifications, thus posing a threat to patient safety.

\section{INADEQUATE INFORMED CONSENT AND RECONSENT}

Currently, these documents are often lengthy, written in legal language and, therefore, difficult to understand. Instead, informed consent forms and reconsent procedures should be clear, accurate and limited to what is relevant for the patient. Ethics committees should see to it that consent forms serve their primary purpose-to inform the patientand patients themselves should be involved in their design.

\section{OVERINTERPRETATION OF REGULATIONS AND GUIDELINES}

There is a pressing need to review and rewrite guidance documents, in particular the International Council for Harmonisation (ICH) E6: Good Clinical Practice (GCP), to address textual ambiguity. Imprecise and vague texts leave the door open to overinterpretation of regulations, leading for instance to excessive on-site monitoring and increasing the cost of clinical trials disproportionately. There is widespread concern that potential overinterpretation of General Data Protection Regulation (GDPR) requirements will add to the administrative burden on researchers. Ultimately, GCP guidelines need to be clear, concise, consistent and proportionate. ${ }^{4}$

To address these issues, a more flexible and adaptable regulatory environment is needed. It is unquestionable that safety and quality of clinical trials are paramount, yet this should not be used as an excuse to delay muchneeded simplification measures. 
A clear indication that quick and pragmatic adaptation of guidance is possible, without compromising either safety or quality, is the Guidance on the Management of Clinical Trials during the COVID-19 (Coronavirus) pandemic issued by European regulators on 31 March 2020. ${ }^{5}$ The measures to make consent, (remote) monitoring and auditing easier and to facilitate the submission of large multinational trial protocols—although their impact may be offset in part by requirements to register each and every modification-have been widely welcomed by investigators and patients.

More structural and comprehensive measures are needed to overcome the disruption and deceleration of clinical research in Europe due to the accumulation of administrative demands that were visible long before the arrival of COVID-19. ${ }^{6}$ We, therefore, welcome the plans for a thorough revision of the ICH E6(R3) guidelines on Good Clinical Practice. The involvement of patients and healthcare professionals from an early stage is promising, as are the signals that issues around safety reporting, informed consent, textual ambiguity and complexity will be addressed.

The new EU Clinical Trials Regulation No 536/2014 (EU CTR) is in operation since 31 January 2022. According to its own proclamation, the EU CTR is intended to harmonise the evaluation and monitoring processes for clinical trials throughout the EU via a Clinical Trials Information System. So far, the implications are in favour of sponsors and not so much of researchers, but time is needed to see developments.

Europe's medical societies (many of them collaborating within the BioMed Alliance) and patient organisations stand ready and willing to assist the ICH and make this revision of GCP guidelines work.

Pushing back bureaucracy can only be done effectively if the rewriting of guidance is done in a way that reflects the broader need for advancing patient-centred, agile, risk-based clinical trials. Procedures and methods used to ensure GCP compliance should be proportionate to the risks and characteristics of a specific trial/treatment. Targeted guideline revisions need to contribute to a regulatory environment that puts the patient at the centre of clinical research. Reducing bureaucracy and improving patient safety, trial quality, access and affordability go hand in hand.

This statement by the BioMed Alliance is larger than this letter and has specific proposals, especially in relation to safety reporting (https://bureaucracyincts. $\mathrm{eu} /$ ).
This is a collective and urgent appeal by medical associations and patient advocates across disciplines to all involved-in particular, policymakers and regulators at EU and national levels, ethics committees and the pharmaceutical industry-to agree on risk-based pragmatic simplification measures to address the issues mentioned above. The shared goal must be a substantial reduction of bureaucratic obstacles in clinical trials, not (only) as a response to current exceptional circumstances but also on a permanent basis. What is at stake is the efficiency and affordability of clinical trials, and with it the quality of future healthcare and, ultimately and most importantly, patient safety.

Author affiliations

Instituto de Salud Musculoesquelética SL, Madrid, Spain

Twitter Loreto Carmona @carmona_loreto

Contributors The letter was prepared by the collation as a template for dissemination. LC had contributed to the coalition insights and prepared the letter and submitted it.

Funding The authors have not declared a specific grant for this research from any funding agency in the public, commercial or not-for-profit sectors.

Disclaimer This letter has been submitted by the author as EULAR Chair of Advocacy on the name of the members of the "Reducing bureaucracy in clinical trials Coalition", of which EULAR is a signatory, directly, and as member of the BioMed Alliance. Further information on the initiative is available at https:// bureaucracyincts.eu/

Competing interests None declared.

Patient consent for publication Not applicable.

Provenance and peer review Not commissioned; externally peer reviewed.

Open access This is an open access article distributed in accordance with the Creative Commons Attribution Non Commercial (CC BY-NC 4.0) license, which permits others to distribute, remix, adapt, build upon this work non-commercially, and license their derivative works on different terms, provided the original work is properly cited, appropriate credit is given, any changes made indicated, and the use is non-commercial. See: http://creativecommons.org/licenses/by-nc/4.0/.

ORCID iD

Loreto Carmona http://orcid.org/0000-0002-4401-2551

\section{REFERENCES}

1 Lacombe D, Golfinopoulos V, Negrouk A, et al. Clinical research in Europe: who do we do all that for? J Cancer Policy 2020;23:100217.

2 Perez-Gracia JL, Awada A, Calvo E, et al. ESMO clinical research Observatory (ECRO): improving the efficiency of clinical research through rationalisation of bureaucracy. ESMO Open 2020;5:e000662.

3 Rule S, LeGouill S. Bureaucracy is strangling clinical research. BMJ 2019;364:11097.

4 Good clinical trials collaborative, 2021. Available: https://wellcome. org/what-we-do/our-work/good-clinical-trials-collaborative

5 European Commission. Guidance on the management of clinical trials during the COVID-19 (coronavirus) pandemic version 4, 2021. Available: https://ec.europa.eu/health/sites/health/files/files/eudralex/ vol-10/guidanceclinicaltrials_covid19_en.pdf

6 Gribben J, Macintyre E, Sonneveld P, et al. Reducing bureaucracy in clinical research: a call for action. Hemasphere 2020;4:e352. 